\title{
The Modification of Polyurethane Foams Using New Boroorganic Polyols (II) Polyurethane Foams from Boron-Modified Hydroxypropyl Urea Derivatives
}

\author{
Iwona Zarzyka \\ Department of Organic Chemistry, The Faculty of Chemistry of Rzeszow University of Technology, \\ Powstańców Warszawy 6, 35-929 Rzeszow, Poland \\ Correspondence should be addressed to Iwona Zarzyka; izarzyka@prz.edu.pl
}

Received 10 August 2013; Accepted 17 November 2013; Published 22 January 2014

Academic Editors: L. Ballice, Y. Matsuo, and T. N. Ramesh

Copyright (C) 2014 Iwona Zarzyka. This is an open access article distributed under the Creative Commons Attribution License, which permits unrestricted use, distribution, and reproduction in any medium, provided the original work is properly cited.

\begin{abstract}
The work focuses on research related to determination of application possibility of new, ecofriendly boroorganic polyols in rigid polyurethane foams production. Polyols were obtained from hydroxypropyl urea derivatives esterified with boric acid and propylene carbonate. The influence of esterification type on properties of polyols and next on polyurethane foams properties was determined. Nitrogen and boron impacts on the foams' properties were discussed, for instance, on their physical, mechanical, and electric properties. Boron presence causes improvement of dimensional stability and thermal stability of polyurethane foams. They can be applied even at temperature $150^{\circ} \mathrm{C}$. Unfortunately, introducing boron in polyurethanes foams affects deterioration of their water absorption, which increases as compared to the foams that do not contain boron. However, presence of both boron and nitrogen determines the decrease of the foams combustibility. Main impact on the decrease combustibility of the obtained foams has nitrogen presence, but in case of proper boron and nitrogen ratio their synergic activity on the combustibility decrease can be easily seen.
\end{abstract}

\section{Introduction}

Rigid polyurethane foams-based research derives from the need of change of their properties, such as physical (density, water uptake, dimensional stability, and combustibility), mechanical (compressive strength and brittleness), and electric ones (thermal conductivity). One of the main aspects of polyurethane materials manufacturing improvement is the elimination of toxic compounds from the production process and their replacement with environmental friendly ones [1, 2]. Furthermore, works on foams combustibility decrease are currently undergoing-this particular property considerably reduces their employment. The foams' compositional change, aimed at the mentioned decrease, usually causes the deterioration of their functional attributes. Therefore, it seeks to obtain foams with reduced combustibility and fixed mechanical properties [3-6]. It can be reached by the foams cross-link density increase or through azacyclic compounds or nitrogen content in foams. Flame retardants containing phosphorus, boron, and nitrogen are more and more commonly used as well $[7,8]$.

Bearing in mind the polyurethane foams properties modification issue, the work focuses on research oriented at the determination of new boroorganic polyol application possibility in rigid polyurethane foams production. The use of boron in foam compositions results in more organized polymer structure, which significantly and positively influences on their mechanical strength. Furthermore the presence of boron in foams structure decreases their combustibility $[9$, 10].

In this paper, new polyols were obtained by means of ecofriendly substrates, for example, in N, $\mathrm{N}^{\prime}$-bis(2-hydroxypropyl)urea (BHPU) esterified by boric acid (BA) reaction with propylene carbonate (PC) excess. Rigid, foamed polyurethane materials were obtained and tested by means of the above-mentioned polyols and $4,4^{\prime}$-diphenylmethane diisocyanate. The influence of production way of the polyol on properties of new foams was investigated. Then attributes 
TABLe 1: Polyol synthesis conditions and composition.

\begin{tabular}{|c|c|c|c|c|c|c|c|}
\hline Synth. & $\begin{array}{c}\text { Initial molar ratio* } \\
\text { BHPU : BA : PC }\end{array}$ & $\begin{array}{l}\text { Amount of } \mathrm{K}_{2} \mathrm{CO}_{3} \\
\text { (mole/BHPU mole) }\end{array}$ & $\begin{array}{c}\text { Temp. } \\
\left({ }^{\circ} \mathrm{C}\right)\end{array}$ & $\begin{array}{c}\text { Reaction time } \\
\text { (h) }\end{array}$ & $\begin{array}{l}\text { Formal molar ratio } \\
\text { BHPU : } x \text { in product }\end{array}$ & $\begin{array}{c}\mathrm{HN} \\
(\mathrm{mg} \mathrm{KOH} / \mathrm{g})\end{array}$ & Polyol sign \\
\hline 1. & $1: 2: 6$ & 0.12 & 180 & 8 & $1: 5.6$ & $622 \pm 21$ & PA1 \\
\hline 2. & $1: 2: 12$ & 0.12 & 180 & 14 & $1: 11.1$ & $540 \pm 18$ & PA2 \\
\hline 3. & $1: 2: 18$ & 0.12 & 180 & 22 & $1: 16.2$ & $469 \pm 19$ & PA3 \\
\hline 4. & $1: 2: 6$ & 0.12 & 180 & 13.25 & $1: 5.9$ & $687 \pm 22$ & PB1 \\
\hline 5. & $1: 2: 12$ & 0.12 & 180 & 17 & $1: 10.4$ & $626 \pm 20$ & PB2 \\
\hline 6. & $1: 2: 18$ & 0.12 & 180 & 20 & $1: 15.7$ & $523 \pm 17$ & PB3 \\
\hline 7. & $1: 0: 6$ & 0.12 & 160 & 17 & $1: 5.7$ & $526 \pm 18$ & $\mathrm{PC} 1$ \\
\hline 8. & $1: 0: 12$ & 0.12 & 160 & 22 & $1: 11.3$ & $467 \pm 15$ & PC2 \\
\hline 9. & $1: 0: 18$ & 0.12 & 160 & 32 & $1: 16.2$ & $388 \pm 12$ & PC3 \\
\hline
\end{tabular}

$x$ : oxypropylene unit.

* In case of syntheses 1-6 EBU was used directly.

of foams obtained from boron-modified and unmodified hydroxypropyl urea derivatives were juxtaposed and some foams' properties were compared with other reference foams.

\section{Materials and Methods}

\subsection{Syntheses}

2.1.1. Reactions of BHPU with BA-Method 1. In a round bottom flask $176 \mathrm{~g}$ (1 mole) of BHPU was obtained according to the recipe [11] and $124 \mathrm{~g}$ (2 moles) of BA was placed. Then it was heated in an oil bath, with the flask open and continuous stirring to $110^{\circ} \mathrm{C}$ and set stable for approximately 8 hours. The progress of reaction was monitored by determination of acid number and reaction mixture weight loss.

2.1.2. Reactions of BHPU with BA-Method 2. $176 \mathrm{~g}$ (1 mole) of BHPU, $124 \mathrm{~g}$ (2 moles) of BA, and $400 \mathrm{~cm}^{3}$ of xylene were inserted into a round-bottomed flask fitted with a mechanical stirrer, Dean-Stark trap, and reflux-condenser. Then it was heated to $100^{\circ} \mathrm{C}$ and set stable until 2 moles of water were azeotropically distilled. The xylene was distilled off in a rotary evaporator and the reaction's product (EBU) was dried off to a stable weight in a vacuum dryer at $90^{\circ} \mathrm{C}$ and $0.09 \mathrm{MPa}$.

2.1.3. Reactions of BHPU Esterified by BA with Excess of PC. In a three-necked round bottom flask $132 \mathrm{~g}(0.5 \mathrm{~mole})$ of BHPU (EBU) esterified by boric acid and the appropriate amount of PC (pure, Fluka, Switzerland) was placed to reach the molar ratio of reagents of $11: 6,1: 12$ and $1: 18$, and 6.21 or $8.28 \mathrm{~g}$ of potassium carbonate $\left(12.42-16.56 \mathrm{~g} \mathrm{~K}_{2} \mathrm{CO}_{3} / \mathrm{mole}\right.$ EBU; 0.09-0.12 mole $\mathrm{K}_{2} \mathrm{CO}_{3} /$ mole EBU) was added. It was equipped with a reflux-condenser accompanied by a drying tube and a mechanical stirrer and was heated to $180^{\circ} \mathrm{C}$ (Table 1) during continuous stirring. The reaction's progress was monitored by determination of unreacted PC percentage in reaction mixture [12].

2.1.4. Reactions of BHPU with Excess of PC. In a roundbottomed flask $88 \mathrm{~g}(0.5$ mole) of BHPU and such an amount of PC that initial mole ratio of reagents will be, respectively, $1: 6,1: 12$ and $1: 18$, and $8.28 \mathrm{~g}$ of potassium carbonate that is $16.56 \mathrm{~g} / \mathrm{mole}$ BHPU; 0.12 mole/mole BHPU were placed. It was equipped with a reflux-condenser accompanied by a drying tube and a mechanical stirrer and was heated to $160^{\circ} \mathrm{C}$ during continuous stirring. The reaction' progress was monitored by determination of unreacted PC percentage in reaction mixture.

2.1.5. Obtaining Foamed Polyurethane Materials. $10 \mathrm{~g}$ of proper hydroxypropyl urea derivative, $0.1 \mathrm{~g}$ of a surfactant ( $\mathrm{L}$ 6900 Silicon, Momentive, USA), 1.5-4.6 wt\% of triethylamine (TEA, catalyst, pure, Avocado, Germany), and 2-6 wt $\%$ of water (Table 4) were inserted into a $250 \mathrm{~cm}^{3}$ polyethylene cup. Having thoroughly mixed all the components, a properly calculated amount of $4,4^{\prime}$-diphenylmethane diisocyanate (with a triisocyanate additive [MDI], pure, Merck, Germany) was added and later on experimentally corrected. When an isocyanate was added up, it was vigorously stirred until creaming occurred. Times of creaming, expanding, and drying of the foams were measured. With the aim of the next tests, after 48 hours of foams seasoning in room temperature, fittings were cut out of them.

2.2. Methods of Analysis. Hydroxyl number (HN) of the obtained polyols was determined with the use of acetic anhydride and pyridine [13].

Thermogravimetric analysis (DTG and TG) of the abovementioned products were made in ceramic pans in the following registration conditions: temperature range 20$600^{\circ} \mathrm{C}$, registration time $60 \mathrm{~min}$, sample weight $1-2 \mathrm{mg}$, and atmosphere-nitrogen, with the use of a derivatograph Termowaga TGA/DSC, Mettler.

The polyols' molar masses (number-average $\left(\bar{M}_{n}\right)$, weight average $\left(\bar{M}_{w}\right), z$-average $\left.\left(\bar{M}_{z}\right)\right)$ were determined with the use of a gel chromatograph Viscotec T60A equipped with RI detector (of refractive index). Separation was performed by means of two independent columns: PSS SDV (of $7.8 \mathrm{~mm} \times$ $300 \mathrm{~mm}$ dimensions), accompanied by TSK deposits of 100 and $1000 \AA$ pore diameter and the following recording conditions: $25 \pm 0,1^{\circ} \mathrm{C}$, eluent flow rate: $1 \mathrm{~cm}^{3} / \mathrm{min}$, injected sample size: $20 \mu \mathrm{dm}^{3}$, polymer concentration in solution: $5 \mathrm{mg} / \mathrm{cm}^{3}$, analysis time: $30 \mathrm{~min}$, and eluent: THF (distilled from above 


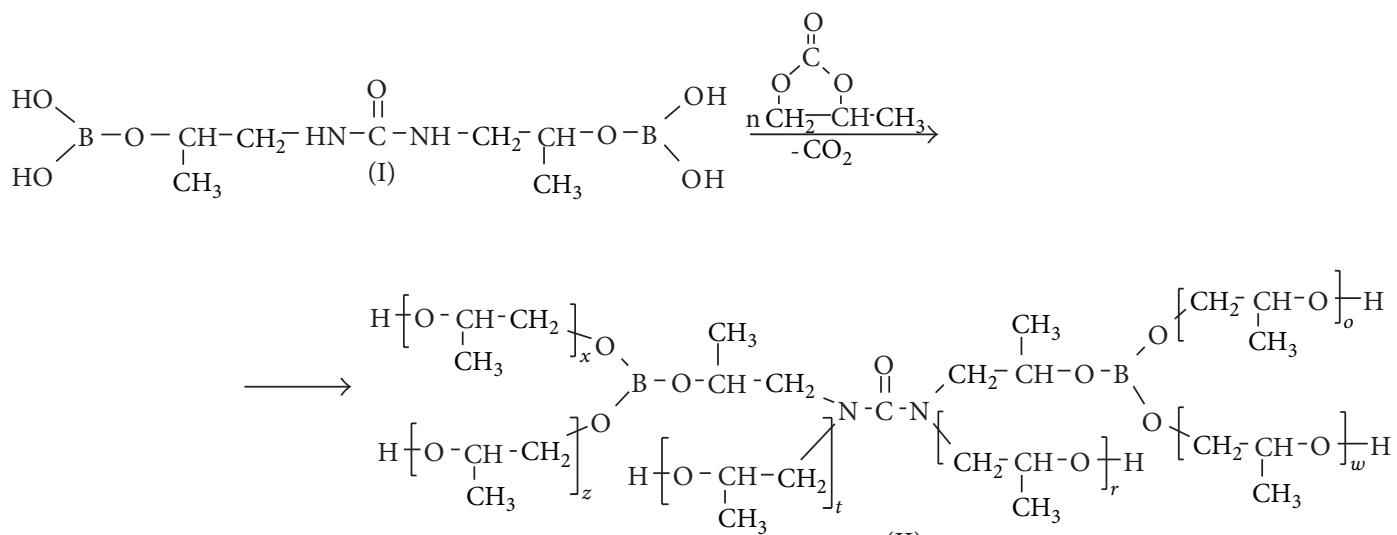

(II)

SCHEME 1

TABLE 2: Thermal stability of hydroxypropyl derivatives of urea.

\begin{tabular}{lcccccc}
\hline Number & Polyol type & $T_{5 \%}\left({ }^{\circ} \mathrm{C}\right)$ & $T_{10 \%}\left({ }^{\circ} \mathrm{C}\right)$ & $T_{20 \%}\left({ }^{\circ} \mathrm{C}\right)$ & $T_{50 \%}\left({ }^{\circ} \mathrm{C}\right)$ & $T_{\max }\left({ }^{\circ} \mathrm{C}\right)$ \\
\hline 1. & PC1 & 130 & 155 & 185 & 215 & 220 \\
2. & PC2 & 230 & 265 & 280 & 320 & 300 \\
3. & PC3 & 170 & 185 & 215 & 260 \\
\hline
\end{tabular}

$T_{x \%}$ : temperature, in which $x \%$ weight loss occurs.

sodium); calibration was performed on the basis of typical polystyrene and branched references.

The elemental analysis $(\mathrm{C}, \mathrm{H}$, and $\mathrm{N}$ ) of foams was made by means of an element analyzer Vario EL III C, H, N, S, and $\mathrm{O}$, manufactured by Elementar. Boron content tests in foams were performed by means of spectrophotometric method [14].

The following polyurethane foams' properties were determined: apparent density [15], water uptake [16], dimensional stability [17], glass transition temperature (by means of DSC method), thermal stability measured by weight loss during monthly annealing at 150 and $175^{\circ} \mathrm{C}$ (one month is required to acquire stable weight), compressive strength [18], thermal conductivity [19], and oxygen index [20].

The microscopic observation of foams was performed at optical microscope Nikon Eclipse LV100 POL, camera Digital Sight DS-5Mc, objective 2,5 or $5 \times$ L Plan. Microscopy measurements were performed in the Biophysical Laboratory of the Department of Physic of Rzeszow University of Technology. The Laboratory has been constructed in the frame of UE Polish Integrated Regional Operation Program.

Measurements of DSC foams were made with the use of DSC822e calorimeter, manufactured by Mettler Toledo, at $20-200^{\circ} \mathrm{C}$ temperature range and heating rate $10 \mathrm{deg} / \mathrm{min}$ in nitrogen atmosphere [21].

Tests on thermal conductivity and heat capacity coefficients were made at room temperature and by means of Isomet 2114 (Applied Precision, Slovakia), portable measuring apparatus. A rebate probe was used in the experiments as well; it required sample of $40 \mathrm{~mm}$ diameter and $80 \mathrm{~mm}$ length [19].

Oxygen index experiment, based on minimal oxygen concentration in oxygen and nitrogen mixture, in which a sample of tested material set in measuring column lights a fire longer than 3 minutes, was performed with the use of a device destined for the oxygen index determination (Fire Testing Technology Limited, UK) [20].

\section{Discussion on the Results}

3.1. Boroorganic Polyols Production and Properties. New boroorganic polyols (II)-boron-modified hydroxypropyl urea-were obtained 8 as a result of EBU (I) with 6-, 12- and 18-molar PC excess reactions at $180^{\circ} \mathrm{C}$ and in the presence of a catalyst-potassium carbonate (Table 1) (also see Scheme 1, where $n=6,12$, and 18).

It should be noted that EBU was produced by means of two methods, which has been described in detail in the work [22]. In the first one BHPU was subject to direct boric acid reaction without any solvent, heating the reagents up to $130^{\circ} \mathrm{C}$. In the latter case BHPU was esterified by boric acid in xylene environment, azeotropically distilling off a proper amount of water. The obtained EBU was used in reaction with excess of PC, thus obtaining two polyol series: A polyols with EBU (according to method 1.-Table 1, synth. 1-3) and B polyols with EBU (according to method 2.-Table 1, synth. 4-6). At the same time, C polyols synthesis was made, but in this case they had no boric groups (Table 1, synth. 7-9).

3.2. Properties of the Obtained Polyols. Thermal stability of the derivatives was measured by means of thermogravimetric method. Polyols obtained without boric acid presence (P1CP3C) are characterized by slightly higher thermal stability than boron-modified polyols; their 5-\% weight loss occurs at $130-230^{\circ} \mathrm{C}$ temperature range (Table 2 ), whereas $5-\%$ weight 
TABLE 3: Molar masses of some obtained polyols determined by means of GPC method.

\begin{tabular}{lccccc}
\hline Number & Polyol type & $\bar{M}_{n}(\mathrm{~g} / \mathrm{mole})$ & $\bar{M}_{w}(\mathrm{~g} / \mathrm{mole})$ & $\bar{M}_{z}(\mathrm{~g} / \mathrm{mole})$ & $\mathrm{HN}(\mathrm{mg}$ KOH$/ \mathrm{g})$ \\
\hline 1. & PC1 & 382 & 388 & 392 & $526 \pm 18$ \\
2. & PC2 & 412 & 418 & 423 & $467 \pm 15$ \\
3. & PC3 & 531 & 538 & 542 & $388 \pm 12$ \\
\hline
\end{tabular}

TABLE 4: Impact of polyol composition on foaming process.

\begin{tabular}{|c|c|c|c|c|c|c|c|}
\hline \multirow{3}{*}{ Polyol type } & \multirow{3}{*}{ Foam type } & \multicolumn{3}{|c|}{ Composition (g/100 g of polyol) } & \multirow{2}{*}{\multicolumn{3}{|c|}{$\begin{array}{c}\text { Foaming process } \\
\text { Time }(\mathrm{s})\end{array}$}} \\
\hline & & Isocyanate* & Water & Catalyst** & & & \\
\hline & & Isocyanate & Water & Cataryst & Creaming & Expanding & Drying \\
\hline PA1 & FA1 & 268 & 3 & 1.73 & 32 & 90 & 10 \\
\hline PA2 & FA2 & 184 & 4 & 2.30 & 37 & 91 & 90 \\
\hline PA3 & FA3 & 144 & 2 & 2.30 & 27 & 77 & 120 \\
\hline PB1 & FB1 & 300 & 4 & 2.59 & 15 & 90 & 10 \\
\hline PB2 & FB2 & 200 & 6 & 4.61 & 16 & 45 & 45 \\
\hline PB3 & FB3 & 160 & 3 & 4.03 & 20 & 70 & 68 \\
\hline $\mathrm{PCl}$ & $\mathrm{FC1}$ & 220 & 2 & 1.54 & 10 & 10 & 1 \\
\hline PC2 & FC2 & 144 & 2 & 2.11 & 15 & 34 & 1 \\
\hline PC3 & FC3 & 112 & 2 & 2.16 & 12 & 83 & 1 \\
\hline
\end{tabular}

${ }^{*} 4,4^{\prime}$-diphenylmethane diisocyanate; ${ }^{* *}$ triethylamine; creaming time: time from start of stirring to start of growth; expanding time: time from start of growth to obtaining final dimensions; drying time: time from the end of foam growth to lack of adhesion of powder materials.

loss of modified polyols occurs at $125-150^{\circ} \mathrm{C}$ temperature range [22]. A and B polyols display similar thermal stability.

Average molar masses of hydroxypropyl urea derivatives were determined by means of gel chromatography (Table 3 ). Polyols mass increases along with the increase of PC excess used in reactions. Molar masses weight average of A polyols fall into $487-603 \mathrm{~g} /$ mole range, while molar masses of B polyols are a bit lower-441-586 g/mole [22]. C polyols, unmodified by boric acid, have the lowest masses (Table 3, numbers 1-3). Moreover, hydroxyl numbers (HN) of the obtained polyols were also determined (Table 1).

3.3. Characteristics of the Foaming Process. Foaming of hydroxypropyl urea derivatives modified and unmodified by boric acid were performed with the presence of MDI (as an isocyanate component). The initial attempts showed that $2-6 \%$ of water is the best amount, as far as foaming is depending on polyol type and on amount of oxypropylene units contained in it. The smallest amount of water (2 wt\%) was applied in manufacturing foams with boron-unmodified polyols (Table 4, P1C-P3C).

Similar relationships can be observed in case of catalyst presence-the smallest amount of it is used, when the oxypropylene units in a polyol is as low as possible (Table 4).

Creaming time of foamed compositions falls into 10$37 \mathrm{sec}$ range-in addition, compositions obtained with polyols with no boron present ( $\mathrm{C}$ polyols) are characterized by the shortest creaming time, while the longest one sticks to A polyols. Such relations can occur in case of expanding and drying times (Table 4), but foams from $\mathrm{C}$ polyols (boronunmodified) are almost completely dry after the end of expanding time (Table 4, P1C-P3C).

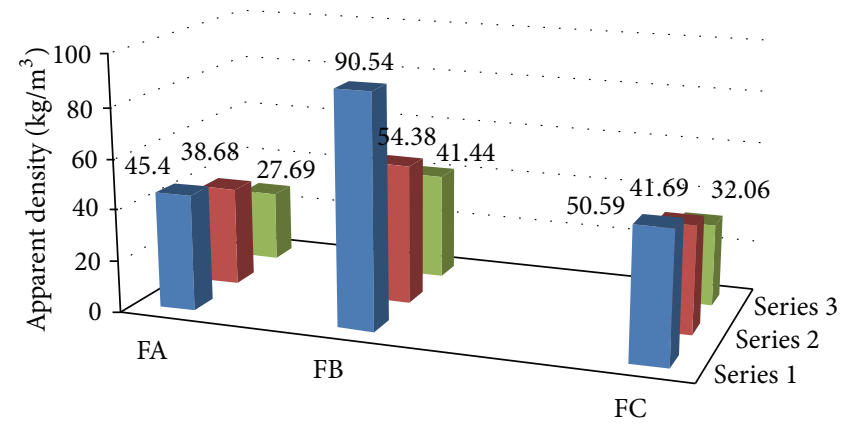

FIGURE 1: Apparent density of polyurethane foams.

3.4. Polyurethane Foams Properties. Apparent density of the boron-modified foams obtained from A polyols falls into a range typical for polyurethane foams $28-44 \mathrm{~kg} / \mathrm{m}^{3}$ (Figure 1, FA). It has been observed that the density decreases along with the increase of oxypropylene units in a polyol, so with the decrease of boron content in a foam.

Similar relationships can be seen in case of foams obtained from B polyols, but their density values are significantly higher $\left(41-90 \mathrm{~kg} / \mathrm{m}^{3}\right)$. The boron-unmodified foams are characterized by density falling within $32-51 \mathrm{~kg} / \mathrm{m}^{3}-$ analogous to foams obtained from A polyols. It should be noticed, however, that foams densities obtained from $\mathrm{C}$ polyols increase together with the increase of the amount of oxypropylene units in a polyol component, whereas in cases of $\mathrm{A}$ and $\mathrm{B}$ polyols a reverse effect can be recognized (Figure 1).

Water uptake after 24-hour in-water exposition at room temperature [16] of all boron-unmodified foams is alike and 
TABLE 5: Dimensional stability of polyurethane foams.

\begin{tabular}{|c|c|c|c|c|c|c|}
\hline \multirow{3}{*}{ Foam type } & \multicolumn{6}{|c|}{ Dimensional stability (linear \%) in $150^{\circ} \mathrm{C}$} \\
\hline & \multicolumn{2}{|c|}{ Length } & \multicolumn{2}{|c|}{ Width } & \multicolumn{2}{|c|}{ Thickness } \\
\hline & After $20 \mathrm{~h}$ & After $40 \mathrm{~h}$ & After $20 \mathrm{~h}$ & After $40 \mathrm{~h}$ & After $20 \mathrm{~h}$ & After $40 \mathrm{~h}$ \\
\hline FA1 & $1.96 \pm 0.03$ & $1.96 \pm 0.05$ & $2.86 \pm 0.09$ & $2.86 \pm 0.09$ & $2.68 \pm 0.23$ & $2.65 \pm 0.23$ \\
\hline FA2 & $0.84 \pm 0.03$ & $0.84 \pm 0.04$ & $1.11 \pm 0.03$ & $1.11 \pm 0.03$ & $0.99 \pm 0.07$ & $0.99 \pm 0.09$ \\
\hline FA3 & $1.32 \pm 0.11$ & $1.76 \pm 0.13$ & $0.13 \pm 0.03$ & $1.39 \pm 0.50$ & $0.45 \pm 0.03$ & $0.90 \pm 0.04$ \\
\hline FB1 & $0.64 \pm 0.05$ & $0.64 \pm 0.06$ & $0.00 \pm 0.00$ & $0.68 \pm 0.02$ & $0.00 \pm 0.00$ & $0.00 \pm 0.00$ \\
\hline FB2 & $0.15 \pm 0.02$ & $0.75 \pm 0.05$ & $0.52 \pm 0.02$ & $2.09 \pm 0.06$ & $0.00 \pm 0.00$ & $1.06 \pm 0.11$ \\
\hline FB3 & $1.91 \pm 0.12$ & $2.23 \pm 0.67$ & $0.54 \pm 0.04$ & $0.45 \pm 0.02$ & $0.48 \pm 0.06$ & $0.68 \pm 0.09$ \\
\hline $\mathrm{FC1}$ & $18.40 \pm 1.50$ & $16.89 \pm 1.28$ & $16.11 \pm 1.93$ & $15.98 \pm 1.79$ & $3.91 \pm 0.42$ & $8.59 \pm 0.76$ \\
\hline FC2 & $7.87 \pm 0.26$ & $9.55 \pm 0.23$ & $5.51 \pm 0.43$ & $8.27 \pm 0.55$ & $6.25 \pm 0.29$ & $10.42 \pm 0.72$ \\
\hline FC3 & $8.28 \pm 0.82$ & $9.08 \pm 1.01$ & $14.58 \pm 1.38$ & $15.23 \pm 1.54$ & $15.94 \pm 1.60$ & $19.81 \pm 2.02$ \\
\hline
\end{tabular}

TABLE 6: Polyurethane foams thermal stability.

\begin{tabular}{lccccc}
\hline Foam type & $T_{5 \%}\left({ }^{\circ} \mathrm{C}\right)$ & $T_{10 \%}\left({ }^{\circ} \mathrm{C}\right)$ & $T_{20 \%}\left({ }^{\circ} \mathrm{C}\right)$ & $T_{50 \%}\left({ }^{\circ} \mathrm{C}\right)$ & $T_{\max }\left({ }^{\circ} \mathrm{C}\right)$ \\
\hline FA1 & 210 & 235 & 255 & 310 & 210,240 and 315 \\
FA2 & 230 & 250 & 250 & 305 & 260 and 315 \\
FB1 & 185 & 210 & 235 & 300 & 260 and 310 \\
FB2 & 190 & 235 & 245 & 300 & 265 and 315 \\
FC1 & 180 & 220 & 240 & 420 & 260 \\
FC2 & 180 & 200 & 440 & 136 \\
\hline
\end{tabular}

$T_{x \%}$ : temperature, in which $x \%$ weight loss takes place.

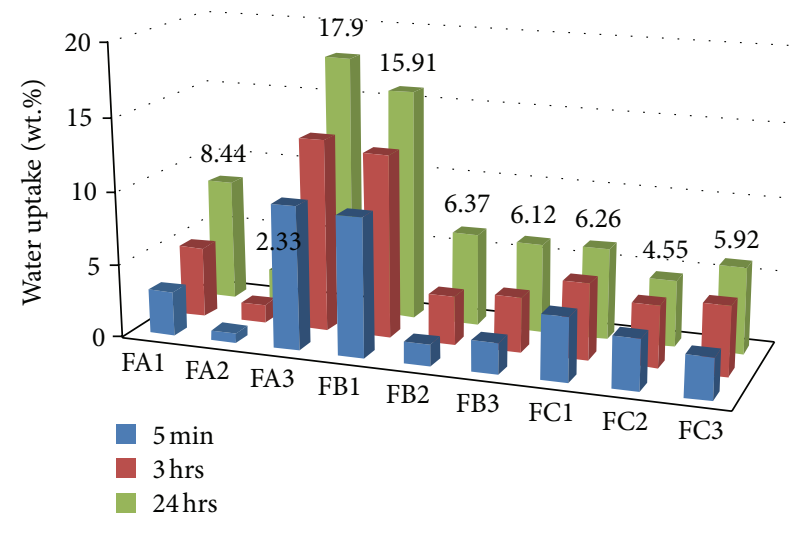

FIGURE 2: Water uptake of polyurethane foams.

comprises into $4.6-6.3 \mathrm{wt} \%$ range. It is also usually smaller than in the case of the boron-modified ones (6.1-17.9 wt\%). One exception are FB2 foams (Figure 2) obtained from A polyol of average boron content, which reveal the smallest (the best) water uptake (2.3 wt\%). This uptake of the modified foams depends on the boron content in given foams (the amount of oxypropylene units) and undergoes changes, but they are not regular ones.

Observations of the foams under an optical microscope have evidenced that their structure contains mainly closed pores of a regular distribution. In the case of foams obtained from A polyols, wall thickness of the pores is $15-20 \mu \mathrm{m}$ and size of the pores is put in the range of $0.12-0.33 \mathrm{~mm}$. The foams obtained from B polyols have pores of slightly thicker walls of $30-50 \mu \mathrm{m}$ but similar sizes of $0.11-0.30 \mathrm{~mm}$. Furthermore, it was noted that pores of the foams prepared with the contribution of A polyols have sharp-edged shapes, while those of the foams obtained from B polyols are more rounded (Figure 3 ).

Insertion of boron into structure of foams increases their dimensional stability (Table 5), while the boron content changes' impact on regular dimensional foam modification has not been observed so far. Yet, unmodified foams' dimensional changes fall into 4-20\% linear values (Table 5, FC1-FC3), whereas the same changes, in case of all boronmodified foams, do not exceed 3\% linear values. What is more, slightly smaller modifications apply to foams obtained from B polyols (Table 5; FA1-FA3, FB1-FB3).

Glass transition temperature $\left(T_{g}\right)$ of the boron-modified, foamed polyurethane materials, determined by the DSC method, ranges at $127-162^{\circ} \mathrm{C}$ (Table 6). The glass transition temperature values of foams obtained from proper $\mathrm{A}$ and $\mathrm{B}$ polyols are comparable (Table 6; FA1 and FB1, FA2 and FB2). The glass transition temperature values of foams obtained from $\mathrm{C}$ polyols (the boron-unmodified) is lower than in the corresponding modified foams (Table 6).

It has also been noticed that glass transition temperature of the modified foams decreases along with the increase of oxypropylene units in a polyol (e.g., the decrease of boron content), while the glass transition temperature of unmodified foams increases together with the increase of the oxypropylene units in a polyol (Table 6).

The glass transition temperature of all foams is higher than room temperature, which allows qualifying the obtained foams as the rigid ones [23]. 

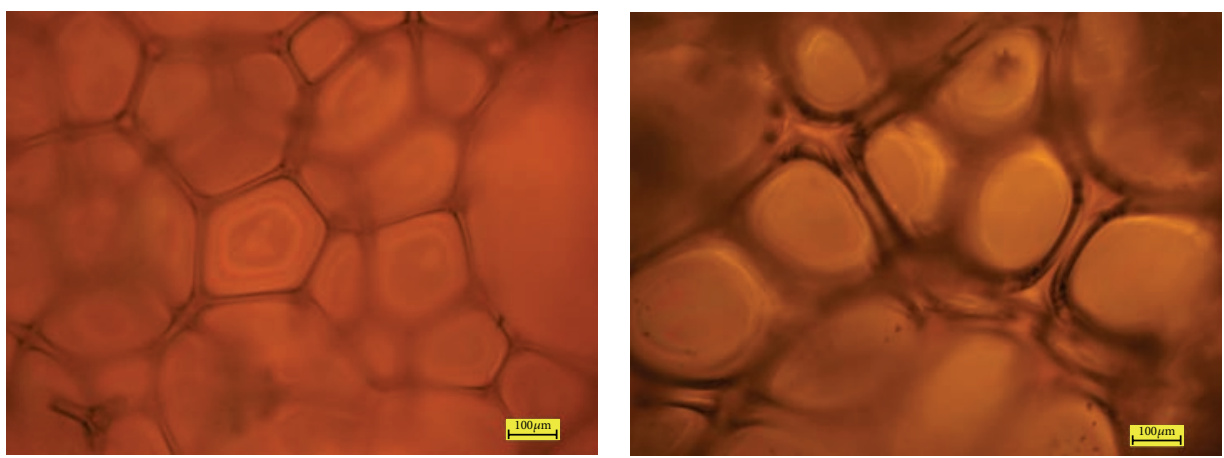

Figure 3: Morphology of foams: (a) FA1 and (b) FB1, magnification 10x.

Thermogravimetric analysis showed high thermal stability of the obtained polyurethane foams (Table 6). 5\% weight loss of foams obtained from A polyols occurs only at temperature range $210-230^{\circ} \mathrm{C}$ (Table 6). As for DTG curve, one can notice that in case of foams obtained from the polyol component with the highest boron content (Table 6, FA1), 3 extremes occur-the first at $210^{\circ} \mathrm{C}$, the second at $240^{\circ} \mathrm{C}$, and the third one at $315^{\circ} \mathrm{C}$. The first extremum appears due to boron groups' decomposition [24], the second due to carbamate groups' decomposition, and the third one due to urea groups' decomposition [25]. Foams obtained in the presence of PA2 polyols show two DTG curve extremesthe first at $260^{\circ} \mathrm{C}$ (simultaneous decomposition of boron and carbamate groups) and the second at $315^{\circ} \mathrm{C}$ (Table 6, FA2).

Foams obtained from $\mathrm{B}$ polyols are characterized by slightly smaller thermal stability; $5 \%$ weight loss occurs in temperature around $190^{\circ} \mathrm{C}$ (Table 6; FB1 and FB2), whereas the foams DTG curve shows two extremes-as in the preceding example - at $260^{\circ} \mathrm{C}$ and $310^{\circ} \mathrm{C}$ (Table 6, FB1 and FB2).

The thermal stability of all boron-modified foams is higher in comparison with the unmodified ones but is considerably higher in case of A polyol foams than in case of B polyol ones (Table 6). 5\% weight loss of the unmodified foams occurs in $180^{\circ} \mathrm{C}$. Yet, on the boron-unmodified foams DTG curve only one extremum can be observed-at $260^{\circ} \mathrm{C}$ (Table 6; FC1 and FC2).

In order to test the thermal resistance of the obtained polyurethane foams, they were exposed to 150 and $175^{\circ} \mathrm{C}$ temperature until stable weights occurred (approximately 30 days) (Table 7 , Figure 3). As for $150^{\circ} \mathrm{C}$ temperature, weight losses lower than $10 \%$ apply to almost every foam type obtained from B polyols and those foams get from A polyols, which are characterized by higher boron content (Table 7; FB1-FB3 and FA1, FA2). This means that the abovementioned foams may be applied at $150^{\circ} \mathrm{C}$ temperature.

On the other hand, weight losses of the unmodified foams reach up to $20 \%$ (Table 7; FC1-FC3; Figure 4).

Due to large weight loss of the obtained foams in the presence of PA3 polyols, reaching $15.4 \%$, and foams from PB3 polyols amounting to $10 \%$, such foams are not taken into consideration in case of other properties' investigation. Foams obtained from C polyols (FC1 and FC2), however, were tested despite large weight losses because they are foams of reference.
TABLE 7: Foams weight loss following the 30-day annealing.

\begin{tabular}{lcc}
\hline Foam type & $\begin{array}{c}\text { Foam weight loss (wt\%) following the annealing } \\
\text { in a given temperature }\left({ }^{\circ} \mathrm{C}\right)\end{array}$ \\
& 150 & 175 \\
\hline FA1 & $6.52 \pm 0.01$ & $23.61 \pm 0.91$ \\
FA2 & $7.54 \pm 0.23$ & $23.86 \pm 0.01$ \\
FA3 & $15.42 \pm 0.67$ & $41.03 \pm 0.58$ \\
FB1 & $3.68 \pm 0.48$ & $16.00 \pm 0.11$ \\
FB2 & $7.32 \pm 0.51$ & $21.95 \pm 0.91$ \\
FB3 & $9.65 \pm 0.75$ & $25.85 \pm 1.30$ \\
FC1 & $21.57 \pm 0.13$ & $29.47 \pm 0.06$ \\
FC2 & $24.74 \pm 0.02$ & $26.75 \pm 0.04$ \\
FC3 & $37.48 \pm 0.35$ & $41.06 \pm 1.02$ \\
\hline
\end{tabular}

In temperature reaching up to $175^{\circ} \mathrm{C}$ such losses are considerably higher, while the smallest weight losses (1626\%) apply to foams from B polyols (Table 7; FB1-FB3). The other modified (from A polyols) and unmodified foams (from C polyols) display deficiencies amounting even up to $40 \%$ (Table 7 ).

In general, the unmodified foams weight losses are much larger than the modified ones but we can notice that in higher temperatures differences between weight losses of modified and unmodified foams being smaller.

The obtained foams were strength tested, performing these tests before annealing and after $150^{\circ} \mathrm{C}$ annealing (but only those that showed weight loss below 10\%). All foams were compressed parallel to the direction of their growth, measuring their compressive strength accompanied by $10 \%$ deformation.

Foams obtained from A polyols possess compressive strength ranging from 0.1 to $0.22 \mathrm{MPa}$ (Table 8 ; FA1-FA3). The strength change does not depend directly neither on boron content in given foams nor on foam's density (Figure 1, Table 10; FA1-FA3). Foams of average boron content and average apparent density $\left(38.7 \mathrm{~kg} / \mathrm{m}^{3}\right.$; Figure 1; FA2) display the highest compressive strength-0.22 MPa (Table 8, FA2).

Foams compressive strength increases after temperature exposition at $150^{\circ} \mathrm{C}$-the largest growth occurs in case of 


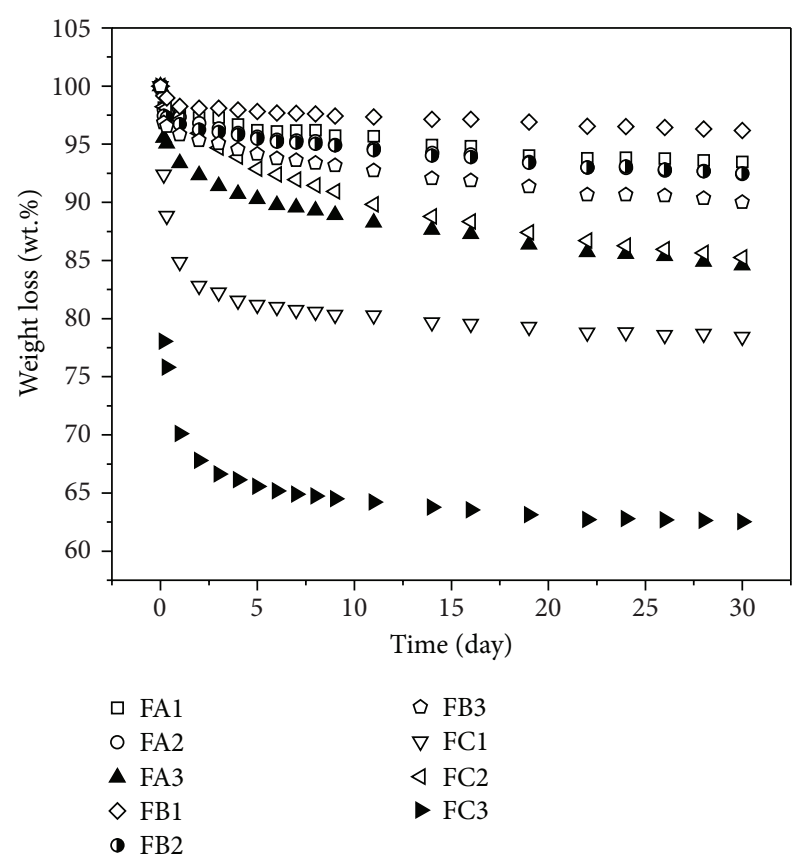

FIGURE 4: Comparison of heat resistance of the boron-modified and unmodified foams on the basis of their 30-day annealing at $150^{\circ} \mathrm{C}$.

foams with the highest boron content. All foams A, annealing at $150^{\circ} \mathrm{C}$, show almost identical compressive strength, which does not depends on boron content (Table 8; FA1 and FA2).

Foams obtained from B polyols possess higher compressive strength: $0.28-0.54 \mathrm{MPa}$ (Table 8 ; FB1-FB3). The influence of the boron content on the foams compressive strength can be clearly seen here; along with the boron content decrease, the foams' compressive strength deteriorates as well. It should also be noted that the foams obtained from $\mathrm{B}$ polyols possess higher apparent density, what impacts on their compressive strength (Figure 1 and Table 8; FA1FA3 and FB1-FB3). Juxtaposing the strength of A and B polyol foams of almost identical density (Figure 1; FA2 and FB3); it is visible that the $\mathrm{B}$ ones display higher strength accompanied by lower boron content (Table 8; FA2 and FB3). After successful temperature exposition at $150^{\circ} \mathrm{C}$, the $\mathrm{B}$ foams compressive strength increases, but only in case of foams with the lower boron content (Table 8; FB1-FB3).

Comparing the compressive strength of the unmodified, 0.02-0.04 MPa (Table 8, FC1-FC3), and modified foams, 0.10-0.54 MPa (Table 8; FA1-FA3 and FB1-FB3), the boron content has significant impact on the increase of this property. Taking into account the influence of the apparent density on the foams' strength (Figure 1 and Table 8; FC2, FA2 and FB3; FB2 and FC3; FC1 and FA3), it can be stated that the abovementioned increase is 5 -15-times greater.

What is more, the compressive strength of the obtained foams was compared with the same property of typical foams (0.24 MPa) obtained with the use of Rokopol RF-55 and MDI of similar apparent density $\left(36.9 \mathrm{~kg} / \mathrm{m}^{3}\right)$ [26]. It has been claimed that the boron-modified foams obtained from B polyols (Table 8, FB3) possess higher compressive strength $(0.28 \mathrm{MPa})$. Nevertheless, their compressive strength is lower
TABLE 8: Compressive strength of the obtained polyurethane foams.

\begin{tabular}{lccc}
\hline $\begin{array}{l}\text { Foam } \\
\text { type }\end{array}$ & $\begin{array}{c}\text { Compressive strength } \\
\sigma_{M}(\mathrm{MPa})\end{array}$ & \multicolumn{2}{c}{$\begin{array}{c}\text { Compressive strength after } \\
\text { annealing at } 150^{\circ} \mathrm{C}\end{array}$} \\
\hline FA1 & $0.10 \pm 0.004$ & $0.34 \pm 0.014$ & 340 \\
FA2 & $0.22 \pm 0.007$ & $0.36 \pm 0.012$ & 164 \\
FA3 & $0.18 \pm 0.007$ & - & - \\
FB1 & $0.54 \pm 0.022$ & $0.92 \pm 0.016$ & 70 \\
FB2 & $0.31 \pm 0.019$ & $0.41 \pm 0.013$ & 132 \\
FB3 & $0.28 \pm 0.012$ & $0.32 \pm 0.007$ & 114 \\
FC1 & $0.04 \pm 0.002$ & - & - \\
FC2 & $0.04 \pm 0.002$ & - & - \\
FC3 & $0.02 \pm 0.001$ & - & - \\
\hline
\end{tabular}

than that of condensation polyurethanes with different hard segments [27].

Insulation parameters have been tested and due to these experiments it has been claimed that the thermal conductivity decreases along with the increase of foam boron content (Table 9; FA1 and FA2; FB1 and FB2). Foams obtained from $A$ and $B$ polyols containing lower amount of boron have the identical thermal conductivity value (Table 9; FA2 and FB2). On the other hand, foams of higher boron content, obtained from B polyols, display lower thermal conductivity, $0.0308(\mathrm{~W} /(\mathrm{m} \cdot \mathrm{K}))$, than foams obtained from A polyols, $0.0321(\mathrm{~W} /(\mathrm{m} \cdot \mathrm{K}))$ (Table 9, FA1); thus, they possess better heat-insulating properties. Furthermore, it has been observed that the thermal conductivity of these foams is lower than $0.035(\mathrm{~W} /(\mathrm{m} \cdot \mathrm{K}))$, so it is typical for polyurethane foams to be employed as insulation materials [28].

Having examined the insulation parameters of the modified and unmodified foams, it has been said that the thermal conductivity of the modified ones is lower (Table 9).

What is more, in case of the boron-modified foams obtained from A and B polyols the thermal conductivity increases together with the volume heat capacity (Table 9; FA1 and FA2; FB1 and FB2); thus, the better insulation, the worse heat accumulation [28].

The volume heat capacity of the unmodified foams is usually lower than the corresponding modified ones (Table 9), but when the thermal conductivity increases, the volume heat capacity decreases, so it is the opposite situation than in case of the modified foams.

In order to illustrate the influence of the boron content on the decrease of the combustibility of the obtained polyurethane foams, their OI has been determined (Figure 5). Comparing the OI values of the obtained foams (Figure 5; FA1 and FA2; FB1 and FB2) with the OI value of a typical foams obtained in the presence of Rokopol RF-55 and MDI amounting to $19.6 \%$ [10], a clear impact of the boron presence on the combustibility decrease can be seen. OI value increases together with boron content in foams (Figure 5, FA1 and FA2; FB1 and FB2). On the basis of the OI value it can be said that foams obtained from A polyols (Figure 5, FA1 and FB1), as well as foams of higher boron content obtained from $\mathrm{B}$ 
TABLE 9: Insulation parameters.

\begin{tabular}{|c|c|c|}
\hline Foam type & Thermal conductivity, $\lambda(\mathrm{W} /(\mathrm{m} \cdot \mathrm{K}))$ & Volume heat capacity, $C_{\rho} \cdot 10^{-6}\left(\mathrm{~J} /\left(\mathrm{m}^{3} \cdot \mathrm{K}\right)\right)$ \\
\hline FA1 & $0.0321 \pm 0.0007$ & $0.0798 \pm 0.0008$ \\
\hline FA2 & $0.0375 \pm 0.0016$ & $0.0885 \pm 0.0030$ \\
\hline FB1 & $0.0308 \pm 0.0003$ & $0.0685 \pm 0.0008$ \\
\hline FB2 & $0.0375 \pm 0.0003$ & $0.0784 \pm 0.0008$ \\
\hline $\mathrm{FCl}$ & $0.0564 \pm 0.0001$ & $0.0583 \pm 0.0003$ \\
\hline FC2 & $0.0382 \pm 0.0003$ & $0.0868 \pm 0.0001$ \\
\hline
\end{tabular}

TABLE 10: Content of boron and nitrogen in the obtained foams.

\begin{tabular}{lcc}
\hline Foam type & Boron content $(\mathrm{wt} \%)$ & Nitrogen content $(\mathrm{wt} \%)$ \\
\hline FA1 & 0.833 & 9.15 \\
FA2 & 0.616 & 8.12 \\
FB1 & 0.851 & 8.95 \\
FB2 & 0.703 & 8.07 \\
FC1 & 0 & 8.98 \\
FC2 & 0 & 7.66 \\
\hline
\end{tabular}

polyols (Figure 5, FB1), are self-extinguishing (OI higher than 21\%) [29]. It has also been proved that foams obtained from B polyols of higher boron content (Figure 5, FB1), having been fired, extinguish spontaneously, whereas foams of lower boron content (Figure 5, FB2) die down in approximately 1 minute. Such phenomenon was not observed in case of foams obtained from A polyols.

Comparing the OI values of the boron-modified and unmodified foams influence of the boron presence on the OI value of foams obtained in the presence of a polyol component, obtained from larger excess of PC, so containing lower amount of boron (Figure 5; FA2, FB2 and FC2), has been observed.

The determined OI values show that nitrogen in foams (urea groups) should also be taken into consideration because it causes the decrease of the combustibility. When the nitrogen content is higher, foams obtained from polyols obtained with 6-molar PC excess of boron-modified and unmodified have almost identical OI values (Figure 5; FA1, FB1 and FC1), but a bit higher possess the unmodified ones. It has been pointed out that in case of $9 \mathrm{wt} \%$ nitrogen content in foams (Table 10), the boron presence has no impact on the decrease of their combustibility. The boron-modified foams obtained from polyols with more oxypropylene units (Figure 5; FA2, and FB2), so lower nitrogen content (about $8 \mathrm{wt} \%$ ), display higher OI value in comparison with the unmodified ones (Figure 5; FA2, FB2, and FC2). Thus, synergic boron and nitrogen activity related to the foams combustibility decrease can be observed. Nevertheless, the OI value of such foams is lower than those with higher nitrogen content (Figure 5).

\section{Recapitulation and Conclusions}

(1) Rigid, foamed polyurethane materials displaying good dimensional and thermal stability are obtained in the presence of hydroxypropyl urea derivatives of boron-modified.

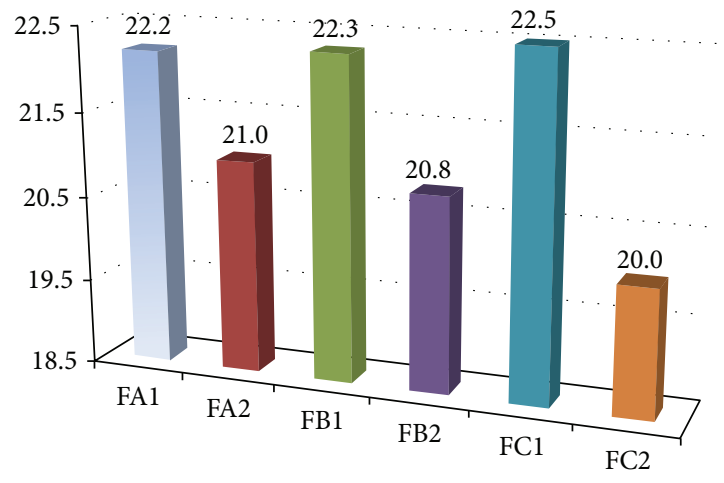

Figure 5: Foam oxygen index values (OI).

(2) The insertion of boron into the foams' structure causes that they can be applied even at $150^{\circ} \mathrm{C}$.

(3) The polyurethane foams boron modification evokes a significant compressive strength increase, as well as influences their insulation values in comparison with both foams obtained from the unmodified urea derivatives and other foams obtaining from typical polyol components.

(4) Nitrogen has a main impact on the combustibility decrease of the obtained foams, but in case of proper boron and nitrogen ratio, their synergic activity on the combustibility decrease can be easily seen.

(5) Foams of better properties were obtained with the presence of a polyol component obtained as a result of the $\mathrm{N}, \mathrm{N}^{\prime}$-bis(2-hydroxypropyl)urea esterified by boric acid reaction accompanied by xylene.

\section{Conflict of Interests}

The author declares that there is no conflict of interests regarding the publication of this paper.

\section{References}

[1] K. Hill, "Fats and oils as oleochemical raw materials," Pure and Applied Chemistry, vol. 72, no. 7, pp. 1255-1264, 2000.

[2] M. Jiang, L. He, W. Gong, L. Dong, H. Xie, and Ch. Xiong, "Enhancement of polymer foam quality by modifying structural and decomposition characteristics of chemical blowing agent," Polymer-Plastics Technology and Engineering, vol. 53, no. 3, pp. 263-267, 2012. 
[3] S.-Y. Lu and I. Hamerton, "Recent developments in the chemistry of halogen-free flame retardant polymers," Progress in Polymer Science, vol. 27, no. 8, pp. 1661-1712, 2002.

[4] A. Prociak, J. Pielichowski, and T. Sterzynski, "Thermal diffusivity of rigid polyurethane foams blown with different hydrocarbons," Polymer Testing, vol. 19, no. 6, pp. 705-712, 2000.

[5] M. V. Alonso, M. L. Auad, and S. Nutt, "Short-fiber-reinforced epoxy foams," Composites A, vol. 37, no. 11, pp. 1952-1960, 2006.

[6] S. Yetkin, H. Unal, A. Mimaroglu, and F. Findik, "Influence of process parameters on the mechanical and foaming properties of PP polymer and PP/TALC/EPDM composites," PolymerPlastics Technology and Engineering, vol. 52, no. 5, pp. 433-439, 2013.

[7] R. E. Myers, E. D. Dickens Jr., E. Licursi, and R. E. Evans, "Ammonium pentaborate: an intumescent flame retardant for thermoplastic polyurethanes," Journal of Fire Sciences, vol. 3, no. 6, pp. 432-449, 1985.

[8] B. Czupryński, J. P. Sadowska, and J. Liszkowska, "Effect of selected boranes on properties of rigid polyurethane-polyisocyanurate foams," Journal of Polymer Engineering, vol. 22, no. 1, pp. 59-74, 2002.

[9] B. Czupryński, J. Liszkowska, and J. Paciorek-Sadowska, "Effect of tri[(3-chloro-2-hydroxy-1-propoxy)-1-butylene] borate on the functional properties of rigid polyurethane-polyisocyanurate foams," Polimery/Polymers, vol. 49, no. 3, pp. 187-190, 2004.

[10] J. Paciorek-Sadowska, B. Czuprynski, and J. Liszkowska, "Ogniobezpieczne poliuretany modyfikowane nowym antypirenem," Chemik, vol. 66, no. 4, pp. 297-306, 2012.

[11] I. Zarzyka-Niemiec and D. Naróg, "Modyfikacja syntezy N,N'bis(2-hydroksy-etylo) i N,N'-bis(2-hydroksypropylo)mocznika," Przemyst Chemiczny, vol. 87, no. 10, pp. 1048-1052, 2008.

[12] M. Kucharski and D. Kijowska, "Synthesis of polyetherols from melamine and propylene carbonate. II," Journal of Applied Polymer Science, vol. 89, no. 1, pp. 104-115, 2003.

[13] Polish (European) Standards: PN-EN ISO, 2554.

[14] Polish (European) Standards: PN-EN, 13346:2002.

[15] Polish (European) Standards: PN-EN ISO 845.

[16] Polish (European) Standards: PN-EN ISO, 2896.

[17] Polish (European) Standards: PN-EN ISO, 2796.

[18] Polish (European) Standards: PN-93C/89071, ISO 884:1978.

[19] Polish (European) Standards: PN ISO, 4589-2:1999.

[20] Polish (European) Standards: PN-EN ISO, 11357-1.

[21] Polish (European) Standards: PN-EN ISO, 13165:2003.

[22] I. Zarzyka, "The modification of polyurethane foams using new boroorganic polyols. I. Obtaining of polyols with the use of hydroxypropyl urea derivatives".

[23] D. Klempner and V. Sendijarevic, Polymeric Foams and Foam Technology, 2nd edition, 2004.

[24] V. V. Nedel'ko, M. Y. Mikhailov, N. V. Chukanov, V. I. Saldin, L. V. Ganina, and V. M. Buznik, "The thermal decomposition of hexamethylenetetraammonium dodecahydro-closo-dodecaborate," Russian Journal of Physical Chemistry B, vol. 5, no. 1, pp. 26-32, 2011.

[25] W. H. Awad and C. A. Wilkie, "Investigation of the thermal degradation of polyurea: the effect of ammonium polyphosphate and expandable graphite," Polymer, vol. 51, no. 11, pp. 2277-2285, 2010.

[26] J. Paciorek-Sadowska, B. Czupryński, J. Liszkowska, and W. Jaskółowski, "Nowy poliol boroorganiczny do produkcji sztywnych pianek poliuretanowo-poliizocyjanurowych. Cz. II.
Otrzymywanie sztywnych pianek poliuretanowo-poliizocyjanurowych z zastosowaniem nowego poliolu boroorganicznego," Polimery, vol. 55, no. 2, pp. 99-105, 2010.

[27] M. Bakar, A. Bialkowska, and J. Szymanska, "Synthesis and evaluation of mechanical and thermal properties of segmented condensation polyurethanes," Plastics Rubber and Composites, vol. 42, no. 5, pp. 203-209, 2013.

[28] H. Garbalińska and M. Bochenek, "Izolacyjność termiczna a akumulacyjność cieplna wybranych materiałów ściennych," Czasopismo Techniczne, vol. 108, pp. 89-96, 2011.

[29] S. Bates and P. Solomon, "Elevated temperature oxygen index apparatus and measurements," Journal of Fire Sciences, vol. 11, no. 3, pp. 271-284, 1993. 

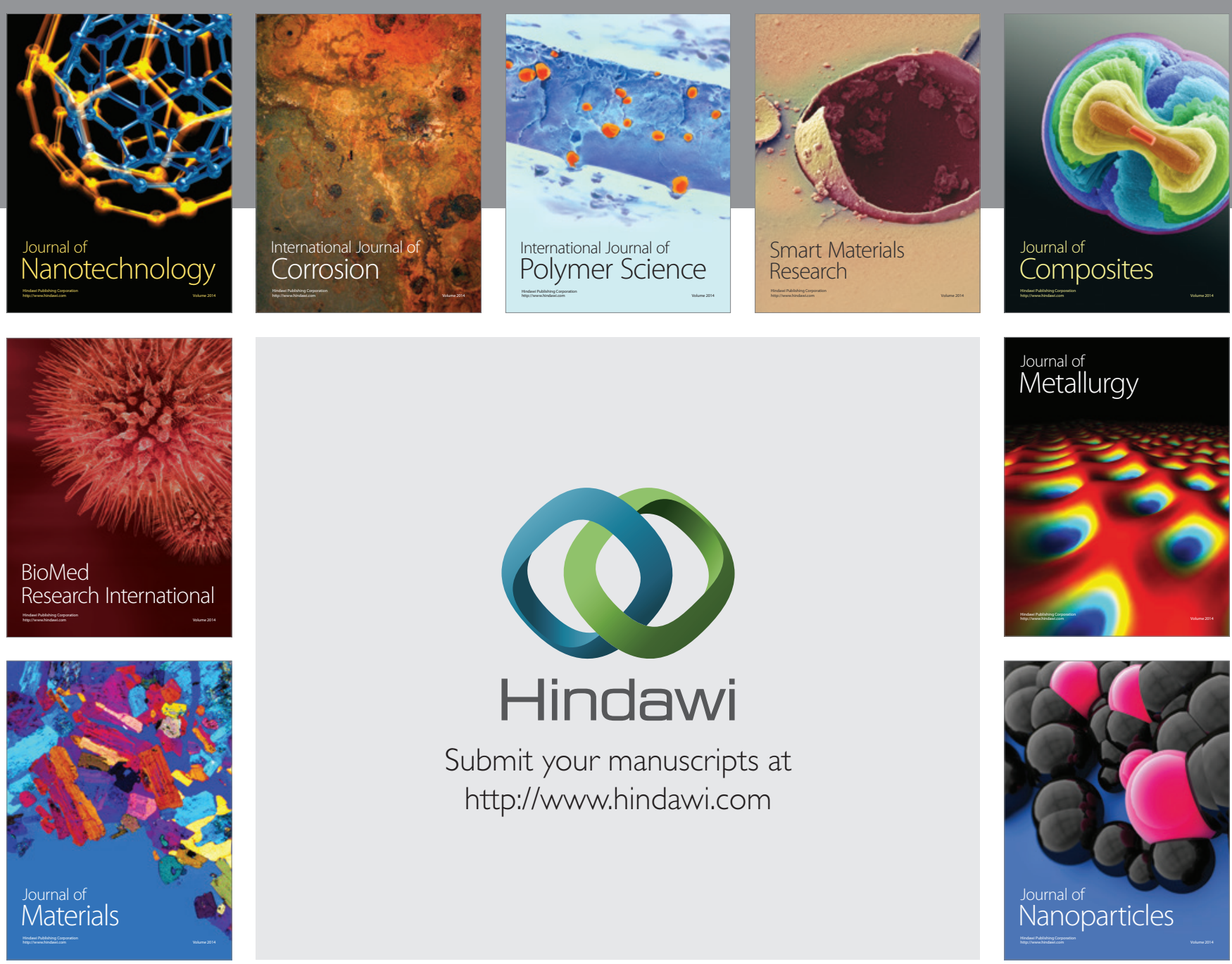

Submit your manuscripts at http://www.hindawi.com
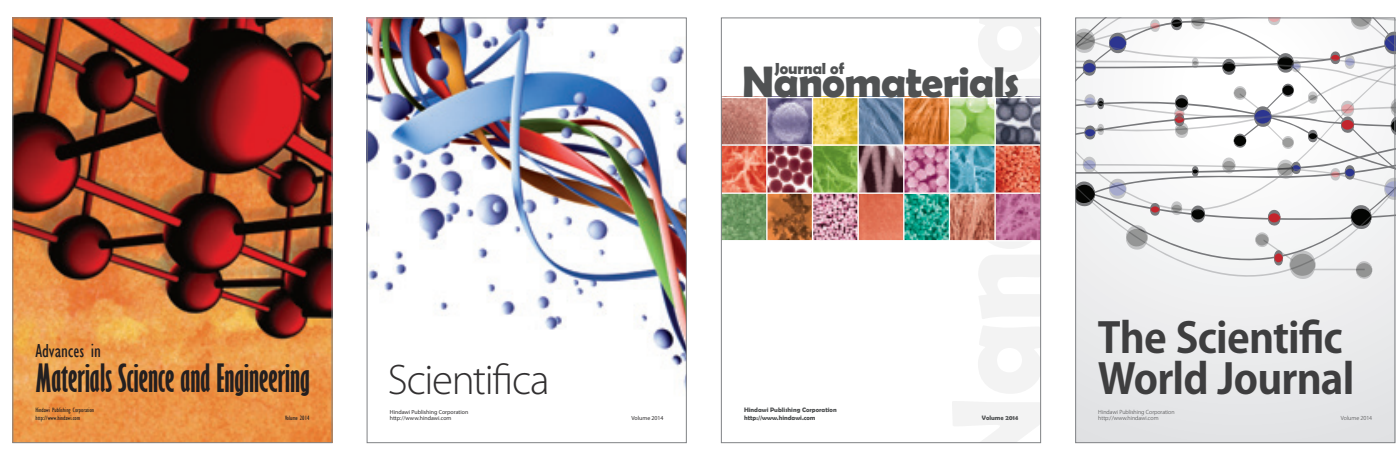

\section{The Scientific World Journal}
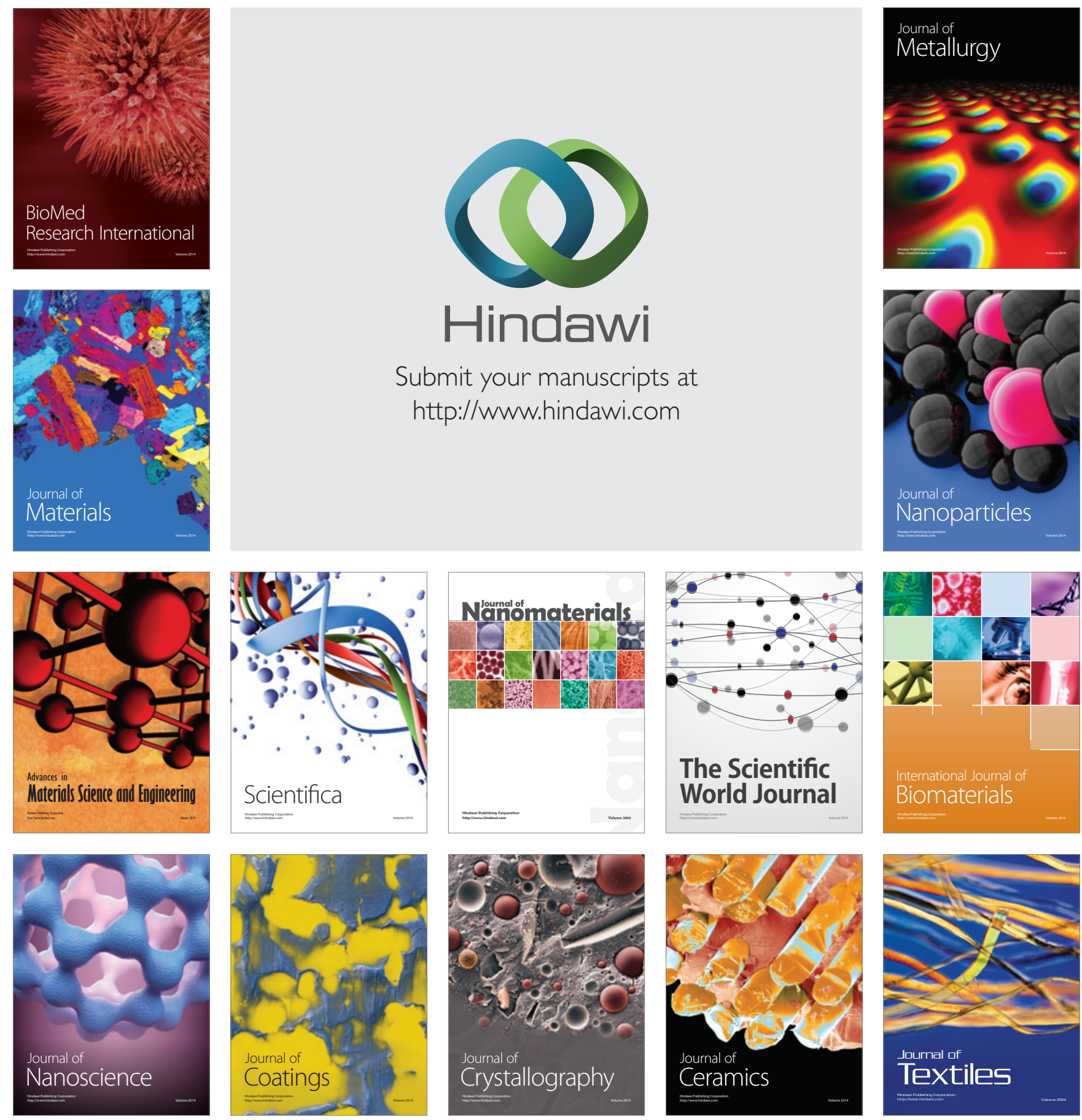